\title{
Jefferson
}

Thomas Jefferson University

$\overline{\text { HOME OF SIDNEY KIMMEL MEDICAL COLLEGE }}$

Jefferson Journal of Psychiatry

Volume 9 | Issue 1

Article 4

January 1991

\section{Depression and Poverty I. Psychosocial and Cultural Determinants}

Donald C. Ohuoha, M.D., M.P.H.

St. Elizabeth's Hospital, Washington DC

Follow this and additional works at: https://jdc.jefferson.edu/jeffjpsychiatry

Part of the Psychiatry Commons

Let us know how access to this document benefits you

\section{Recommended Citation}

Ohuoha, M.D., M.P.H., Donald C. (1991) "Depression and Poverty I. Psychosocial and Cultural Determinants," Jefferson Journal of Psychiatry. Vol. 9 : Iss. 1 , Article 4.

DOI: https://doi.org/10.29046/JJP.009.1.002

Available at: https://jdc.jefferson.edu/jeffjpsychiatry/vol9/iss1/4

This Article is brought to you for free and open access by the Jefferson Digital Commons. The Jefferson Digital Commons is a service of Thomas Jefferson University's Center for Teaching and Learning (CTL). The Commons is a showcase for Jefferson books and journals, peer-reviewed scholarly publications, unique historical collections from the University archives, and teaching tools. The Jefferson Digital Commons allows researchers and interested readers anywhere in the world to learn about and keep up to date with Jefferson scholarship. This article has been accepted for inclusion in Jefferson Journal of Psychiatry by an authorized administrator of the Jefferson Digital Commons. For more information, please contact: JeffersonDigitalCommons@jefferson.edu. 


\title{
Depression and Poverty I. Psychosocial and Cultural Determinants
}

\author{
Donald C. Ohuoha, M.D., M.P.H.
}

\begin{abstract}
The World Health Organization estimates that over 100 million people worldwide suffer from depression, that three times as many may be affected (1). While major advances have occurred in our understanding of the biological aspects of depression, the understanding of psychosocial causes of depression is still largely sketchy. Thus adequate intervention in dealing with this aspect of treatment of depression is scarce.

This paper, divided into two parts, will review recent findings in psychosocial causes of depression and suggest certain strategies for intervention, speculate on the roles of poverty and the issues raised by poverty on the rates of depression and suggest certain strategies for intervention in the treatment of depression amongst the poor.

\section{INTRODUCTION}

The World Health Organization estimates that over 100 million people suffer from depression, that three times as many may be affected (1). It is estimated to cost Americans approximately 16.3 billion dollars annually (2). Amongst the poor, however, it is not clear how many suffer from depression as this population has not been studied very well. In not studying this group, it becomes impossible to estimate their numbers and the human suffering which is often reflected in the psychosocial aspects of their illness, which includes cultural and sociodynamic factors.

Psychosocial factors have been implicated in the development, maintenance, course, and treatment of depression (3), however their specific function in the course of depressive illness remains controversial $(2,3)$. The purpose of this paper is to highlight several psychological and social variables that have been correlated with depression among the poor, speculate on their origins, and then suggest intervention strategies. In part 1 of this paper, the psychological causes of depression among the poor is divided into cultural determinants, attributional style, dysfunctional attitudes and sociodynamic causes. The issues raised by these are also discussed. In part 2, intervention strategies will be discussed.
\end{abstract}

\section{PSYCHOSOCIAL CAUSES OF DEPRESSION IN THE POOR}

\section{Cross Cultural Determinants}

Culture may influence the production of illness, in this case the incidence and prevalence of depression. This can be viewed in terms of the social construction of 
illness that is the pattern of distress, interpretation of that distress as illness, and the response to it. The social network can affect not only the production of depression but it also responds to it. A particular culture may favor certain patterns of illness idioms of distress; the identification by which the distress is known; the local models persons typically construct to explain it; and typical patterns of help seeking, which may influence the course and outcome of disease. Some authors have emphasized the different pathogenic factors which may affect rates of depression in different cultures and the factors affecting its particular manifestation $(4,5)$. The literature on crosscultural psychiatry is full of studies that have addressed differences in the rates of depression across cultures (6-10). However most of these are inconclusive. The problems involved in epidemiological assessment with regards to research in Westerndeveloped countries like uniformity of methods and instruments, and case criteria become even more complicated in cross cultural research. Studies in the epidemiology of depression, though numerous, have yielded only few conclusions about ethnocultural variations in the frequency and distribution of depressive disorders. Until recently most of the information has been anecdotal on systematically collected clinical experiences. Historically, studies of rates of depression in poor communities of western countries and in developing countries have been rare. A review by Prince (11) of depressive illness in Africa divided the literature into reports prior to 1958 , which indicate a low incidence, and reports since 1958, which indicates rates comparable to those in the West. Prince postulated four reasons why there was a reported higher incidence of depression in much of post-Colonial Africa after 1958:

1. Depression was a relatively "prestigious" disease believed to afflict only those who are "especially sensitive or intellectually aware." Prince explained that "in the colonial era depressions should not be seen and named because Africans were not responsible; in the era of independence, depression should be seen because Africans are responsible and aware."

2. Identification of certain clinical presentations as masked depression, especially somatization and neurasthenia which were common, may have led to a more frequent diagnosis of depression. This may have represented a shift in case identification.

3. Patients and families may have viewed mental hospitals as inappropriate places to seek help for the kind of distress that would have been diagnosed as depression. They were more likely to have seen traditional healers, if the depression became too troublesome to be dealt with in the community. Consequently, because of a selection bias against hospital-based treatment for depression, psychiatrists may have underestimated the rates of depression. It should be noted that the attitude noted here is prevalent in Western cultures also and not indigenous only with the under-developed countries of the world.

4. With Westernization and social transformation there may have been a true rise in the rates of depression.

Prince's formulation of the prestige factor to explain the increase, in the 
post-independence era, of the diagnosis of depression recognizes the relationship between the prevailing conceptualization of depression, its interaction with factors arising from the cultural and historical concepts in which it is embeded, and the clinical practices. All of these indirectly put the finger on the effects of illiteracy and poverty. It should be pointed out that in Britain, the definition of melancholy, and its evolution into current concepts of depression, explains in part why there was a reluctance of British colonial psychiatrists to diagnose melancholia (12). Thus people like Robert Burton, who wrote in his work, The English Malady, stated "fools weak or stupid persons, heavy and dull souls are seldom troubled with vapors or lowness of the spirits .... these nervous disorders being computed to make almost $1 / 3$ of the complaints of the people of condition in England" (13). The poor and disinfranchised have also been called weak. Thus Prince's suggestion of the prestige factor may indicate that during colonial periods the diagnosis of depression amongst the inhabitants of the colonies might have been considered tantamount to acknowledging that African and Asian natives or even poor people in general had more in common with the Englishmen and the rich than the colonial rationalization would admit. Thus the prestige factor might not only have predisposed colonial psychiatrists to diagnose depression more frequently, but it may also have left preindependence colonial psychiatrists ill disposed to recognize it as such.

A variety of culturally specific presentations of depression and related local idioms of distress have been reported throughout the world. It has been reported that depressed patients in Afghanistan may complain of weakness and a feeling of a hand squeezing their heart. Obsessive-compulsive patterns have been reported amongst the Japanese, and Indian depressives may be preoccupied with family issues, loss of libido and religion (14). Reports of culture-bound syndromes such as heartbreak syndrome among elderly Mohave Indian men (hiwaitck), genital retraction syndrome in Southeast Asia (Koro), susto in Latin America, different forms of soul loss worldwide $(15,16)$ and other locally constructed idioms of distress (7) seem to address important aspects of the depression experience.

Western patients have been reported to report guilt and self reproach as features of depression. This has been touted as distinguishing them from patients elsewhere. Murphy (17) suggested that this association of guilt with depression may reflect the influence of the Judeo-Christian heritage. Others have, however, indicated that guilt is not so rare amongst Africans or Asians as once believed (18,19,20,21).

\section{ATTRIBUTIONAL STYLE}

Attributions are the answers people give to the question "why"? A negative or biased attributional style has been implicated in persons experiencing depressive symptoms. Abramson et al (22) posited a relationship between expecting events to be uncontrollable and experiencing depression. They described the role of attributions in depression after learned helplessness theory failed to account for the losses of self-esteem or chronic symptoms noted in human depression. They argued that depressed patients will explain negative events appealing to internal global and 
stable causes. This oftentimes is the case among the depressed poor. To explain positive events they will attribute cause to external, specific and unstable factors and are thus lured to these factors in their search for positive events.

Attributional styles can be assessed by the Attributional Style Questionnaire (23). In the so called Hopelessness Theory, Alloy (24) explains that biased thinking plays a central role in depression. There is some agreement that poor depressed patients are more likely than rich depressed patients to attribute the cause of negative events to internal global and stable causes and view themselves, the world and the future, negatively. There is still some controversy with the speculation that poor depressed people (depressed people in general) thinking is less "realistic" than the thinking of non-depressed people. The role poverty plays in this is not understood and will be a topic of some speculation later in this paper.

\section{DYSFUNCTIONAL ATTITUDES}

Beck $(25,26)$ maintains that biases in thinking plays a central role in depression. He explains that this includes a negative view of the self, world, and future. If dysfunctional attitudes have developed during early life experiences that result in inflexible and negative views of oneself the world and future, particularly if this is precipitated by poverty, one can assume that this follows one throughout life. Dysfunctional attitudes may be state dependent (27), making their role as a vulnerability or etiologic factor questionable. However, it is important to note that patients with high Dysfunctional Attitude Scores (DAS) have been shown to be more vulnerable to negative events $(28,29)$.

Abnormal interpersonal relationships contribute to chronic dysfunctional attitude. Interpersonal relationships amongst depressed persons is often abnormal. These persons' difficulty in social interactions is not limited to the family. Tongren and Levinsohn (30) demonstrated that depressed persons compared with nondepressed controls reported deficits in social functioning in groups, which included decreased frequency and comfort in social activity. Coyne (31) suggests that depressed people engender hostility and guilt to their listeners and are therefore at risk for being rejected. It is not clear again how poverty contributes to this and is an area that needs more research.

\section{SOGIODYNAMIG FACTORS AND DEPRESSION}

Several workers have hypothesized that psychosocial stresses adversely affect a person's emotional health. This to a large extent depends on ones ability to cope with various stressors (coping styles). This is also influenced by the availability of adequate social support, by ones age, sex, socio-economic status, mental status and religion. Apart from depression, life stress (including poverty) has been implicated with physical illnesses, like dysfunctional uterine bleeding, end stage renal disease, dermatological disorders, stroke (26), and myocardial infarction (27). 


\section{ISSUES RAISED BY PSYCHOSOCIAL AND SOCIODYNAMIC CAUSES OF DEPRESSION}

The issue of poverty and its interrelations to depression is the main focus of this paper. Earlier we discussed the cultural attitudes and social dynamic influences in the production of illness. The perception of poverty is varied in different cultures. A person might be poor in one culture but may be perceived rich in another. If poverty is related to depression, the interpretation of depression and response to it may be different among different socioeconomic classes, as well as cultures. This may also be true even in intra-cultural perspective. By this I mean the perception of depression and interpretation of it may not be the same in affluent and poor areas of say Washington, D.C. or in similar areas in developing countries. This raises significant questions that must be understood prior to strategies for intervention. If poverty does interact with depression-and if its perception and understanding varies amongst cultures and classes:

1. Does poverty interact with the biological antecedents and effects of depression? In this question the speculation (mine) is that it does. The role of the gene role, nutritional status and other local ecological and biological milieu do effect the rate of depression, eventhough it has not been studied properly. Poor nutritional status, substandard housing, high rates of illness, substance abuse prevalent amongt the poor may contribute to abnormalities in the biochemical causes of depression, even from childhood.

It might be that the chronicity of these conditions and their contributions to depression, even though not perceived as such within these populations, creates a biological environment devoid of clear thinking and planning. There is not much known about the effects of persistent neural discharges and the cognitive adjustment poor people make to live with these conditions, and their contribution to attributional styles and dysfunctional attitudes found in depressed patients. On the other hand, does cultural beliefs and practices within a population, even though poor, affect the physical environ to expose and to deter one from the effects of these biological antecedents (32)? I also speculate that this is true but is an area that needs more study.

Foster (29) noted that the American Indian views time in a much different manner than the Anglo American, perceives time and space as a measurable and ordered entity. He notes that Indians have a focus on the present much like the poor, whose conditions force them to, without any orientation as to future time. This may invariably lead to not planning ahead, not knowing where one is going. It is also sometimes a prelude to atrophy of coping skills, self-medication, and thus leads to disease and abnormalities in neural discharges. On the other hand, these beliefs may also help one to cope with these abnormal discharges when they occur through other mechanisms that are not related to poverty.

2. Does poverty interact with the psychological antecedents and effects of depression? Consider the role of the concept of self among poor people, the 
intense affect brought on by poverty, preferred coping styles and locally defined principles organizing intrapsychic experiences. These all affect the events that cause depression.

In a community where everyone is poor, the effects of poverty and its consequences may not be perceived, and thus may not present a poor concept of self among individuals living in that community. The affects brought on by poverty may not be intense and preferred coping styles may be adaptive and intrapsychic experiences may be one that does not precipitate depression. However, when a poor community is surrounded by an affluent one, the perception of poverty may change and preferred coping styles may be maladaptive and contribute immensely in precipitating depression and may also play a role in the consequent sequellae of the disease. For example, the concept of self amongst people in McLean, Virginia may be the same as those in rural Idaho because these communities are essentially far from each other and day to day interactions amongst the peoples do not occur, even though the culture is the same. What is considered poor in McLean, may be considered rich in Idaho, but because people do not experience that daily, their experiences and thus psychological make-up as it relates to such conditions, is invariably stable. If, however, these two communities that share the same cultural basis are in close proximity, the psychological understanding of self amongst people of these two communities will become altered. Local beliefs and practices then impact in the psychological make-up of the individual and functions as antecedents, either creating vulnerability or affect symptom formation of depression. As another example, Nobles $(34,35,36)$ has emphasized the concept of strong group identification or "we-ness" as a positive Black American trait. Cook and Rono (37) and White (38) have also argued that growth-promoting aspects of Afro American culture and consciousness can positively organize the intrapsychic experience of the individual. These in turn could be used by the individual to cope with the ravages of poverty and depression.

3. Does culture and poverty interact with the social antecedents and effect of depression? The answer to this question is yes. The external and internal social forces on the culture, mores, attitudes and beliefs, also impact on the incidents and manifestations of different rates of depression. What is the role of stereotypes, interpersonal and instutitional (Governments) perceptions, and principles of organizing social relationships on the culture and thus its relationship to depression? The individual whom society by its stereotype is expected to behave a certain way is forced often to live up to that expectation either to maintain an identity, a self-image, or to be accepted. This is true not only in that individuals interaction with the outside or within his or her own group. Do Government's perception of a group or community and does it in turn affect the rate of poverty and thus depression? My speculation is that it does. When Governments accept squalid conditions and fail to improve Social Services, or improve opportunities for employment, this in turn reinforces 
poverty, poor self-esteem and thus leads to greater depression, even though it is not perceived as such among members of such groups. This area has not been studied greatly either and its role to dysfunctionality needs to be studied. The role of societal disruptions, migrations, modernizations, natural disasters and wars as determinant of poverty and their effects on the rates of depression have also not been studied. The effect of war on post-traumatic stress syndrome however is well known. Consider the term "The Good Old Days." What does it mean? That conditions before were better in terms of interpersonal relationships, peoples perception of themselves, or is it a true indictment of modernization? I don't know, but I speculate it's all of the above.

4. Do culture and poverty influence the way people think of depression and related patterns of distress and how does it in turn influence what people think? The answer to this question was alluded to earlier. It addresses the relationship between cosmopolitan (affluent) and local (low socioeconomic) factors of depression.

Culture and poverty do influence the way people think of depression. It affects the way people deal with life events which is known to play a key role in depressive illness (39). In speaking of life events, each culture deals with events differently and thus modulates its impact (increasing or decreasing) on depression. It is clear however that poverty in itself, regardless of cultural belief modulations, is correlated to depression and self-esteem $(39,40)$. Brown, in their sample, found that working class women were more likely than middle class women to become depressed if they experienced a stressful event or major difficulty. If this is so, does it then mean that poor depressed people's thinking is "unrealistic" in the face of consistent stresses and unfavorable life events. This is an area worth studying.

5. Do religious ideologies contribute to or protect from depression? The answer here is again yes, even amongst the poor. The relationship between normal suffering and clinical depression may vary between social classes and cultures. In Buddhist society where normal suffering is often considered intrinsic feature of human condition rather than indication of disorder, the features of depression as defined in standard diagnostic systems, may not apply. Therefore it is imperative that standard diagnostic systems be refined to take into account such local idioms of distress so as to avoid an incorrect diagnosis when such religious beliefs do occur.

\section{SUMMARY}

In the first part of this paper, I have tried to raise significant questions that have yet found very few answers. Depression amongst the poor presents a perplexing question regarding the cause, how it is perceived and the cultural underpinnings that drive or protect individuals from the disease. The phenomena of lived experiences vary across cultures and social strata. There are specific differences in the significance 
of guilt somatization and neurasthenia, one must consider the cultural and historical factors that shape the concepts of depression in a particular culture or socioeconomic group, prior to planning strategies for intervention. These must also be understood so as to prepare ethnographies of the experience of depression among local classes, especially the poor to complement findings from other quatitative methods. When these are understood they will help to create strategies for mental health delivery for this population. The questions raised were done to provoke debate and research in the area with the hope that significant answers will be found that will help improve policy and treatment of this population. In Part II, I will review suggested strategies for intervention.

\section{REFERENCES}

1. Santorius N: Research in effective psychosis within the framework of the WHO programme in M Shon and E Stromgren (Eds) Origin, Prevention and Treatment of Affective Disorders. London: Academic Press, pp 207-13, 1979

2. Hirshfield RMA, Cross CK: Epidemiology of affective disorders, Arch Gen Psych 39:35-37, 1982

3. KashamiJH, Hussain A, Shekim WO, et al: Current perspectives in childhood depression, an overview. Amer J of Psychiatry, 138:143-153, 1981

4. Jilel' WG: Culture-"Pathoplastic" or "Pathogenic" a key question of comparative psychiatry. Curare 5:81-101, 1982

5. Bimabum, K Der Anfbau der Psychose: Conundzllge der Psychiatrischen Strukturanalyse. Berlin Springer Chapter I and II. Translated by H Marshall (1974). The making of psychosis. The principles of structural analysis in psychiatry in SR Hirsch and M Shapiro (Eds) Theme and variations in European Psychiatry: An Anthology pp 197-238, Charlottesville, Va., Univ Press of Va., 1923

6. Singer K: Depressive disorder from a transcultural perspective Soc Sci Med 9:289-301, 1975

7. Marseila AJ: Depressive experience and disorder across cultures in HC Trandis and JG Draguns (Eds) Handbood of cross cultural psychology 6 vols. (vol. 6) pp 237-239. Boston Allyn \& Bacon, 1980

8. Marsella AJ et al: Cross cultural studies of depressive disorders. An overview in A Kleinman and BJ Good (Eds) Culture and depression, pp 299-324. Berkeley Univ of California Press, 1985

9. Bebbington PE: Epidemiology of depressive disorder. Culture Med Psychiatry 2:297-341, 1978

10. Kleiman A: Depression, somatization and the new cross-cultural psychiatry. Soc Sci \& Med 11:3-10, 1977

11. Prince R: The changing picture of depressive syndromes in Africa, is it fact or diagnostic fashion. Canad J African Studies 1:177-192, 1968

12. Murphy HBM, Comparative Psychiatry. The international and intercultural distribution of mental illness. Berlin Sringer-Verlag 116-120, 1982

13. Hunter RA, MacAlpine I: Three hundred years of psychiatry (1535-1860). Corrected reprints Hartsdale N.Y., Carlise Publishing Inc., 1982

14. Sartorius N: Culture and the epidemiology of depression. Psych, Neurol Neurchin (Arist) 76:479-487, 1973 
15. Rubell AJ, O'Neill CW and Collardo-Ardon R: Susto Berkeley, California, Univ of California Press, 1984

16. Schweder RA: Menstrual pollution, soul loss and comparative study of emotions. In Kleiman A and BJ Good (Eds). Culture and depression pp 182-215 Berkeley, California, Univ of California Press, 1985

17. Murphy HBM et al: Cross cultural inquiry into the symptomatology of depression. A preliminary report. Int J Psychiat 3:6-15, 1967

18. Field MJ: Search for security, an ethno-psychiatric study of rural Ghana London: Falser and Falser, 1960

19. Ventoba Rao A: Depressive illness in India. Indian J Psychiat 26:301-311, 1984

20. Taja J et al: Depression across cultures. Br J Psychiat 119:253-260, 1971

21. Ansari SA: Symptomatology of Indian depressives. Trans All-India Inst of Mental Health 9:1-18, 1969

22. Abramson LY, Seligman MEP, Teasdale JD: Learned helplessness in humans: critique and reformulation.J Abnorm Psychol 87:49-74, 1978

23. Peterson C, Semmel A, Baeyer C, et al: The attributional style questionnaire. Cognitive Therapy Research 6:287-300, 1982

24. Alloy LB, Abramson LY, Metalsky GI, et al: The hopelessness theory of depression: attributional aspects. Br J Clin Psychol 27:5-21, 1988

25. Beck AT: Depression Clinical, Experimental and Theoretical Aspects. New York, NY, Harper and Row, 1967

26. Beck AT: Cognitive Therapy and the Emotional Disorders. New York, NY. International University Press, 1976

27. Barrett PA, Gotlib IH: Psychosocial Functioning and Depression Distinguishing Among Antecedents, Concomitants and Consequences. Psychol Bull, 104:97-126, 1988

28. Olinger JL, Kusper NA, Shaw BF: Dysfunctional attitudes and stressful life events: an interactive model of depression. Cognitive Therapy and Research 11:25-40, 1987

29. Wise EH, Barnes DR: The relationship among life events, dysfunctional attitudes and depression. Cognitive Therapy and Research, 10:257-266, 1986

30. Youngren MA, Lewinsohn PM: The functional relation between depression and problematic interpersonal behavior. J Abnorm Psychol, 89:333-341, 1980

31. Coyne JC: Depression and the response of others. J Abnorm Psychol 85:186-193, 1976

32. Brown GW, Harris T: (1978), Social origins of depression: A study of psychiatric disorders in women. N.Y. The Free Press

33. Foster D: Psychiatric Ann 18:699-701

34. Nobles WW, Journal of Afro American Issues 4:22-27, 1976

35. Nobles WW: African Philosophy: Foundations for black psychology. In RL Jones (Ed). Black Psychology 2nd. Ed, N.Y., Harper \& Row (1980).

36. Nobles WW: Extended self: Rethinking the so called Negro self concept. In RL Jones (Ed). Black Psychol, 2nd. Ed. N.Y., Harper \& Row, 1980

37. Cook ND, Kono S (1977): J of Black Psychology 3:18-28

38. White JL: Toward a black psychology. In RL Jones, Ed: Black Psychology 2nd. Ed., N.Y., Harper \& Row, 1980

39. Brown GW, Sklair F, Harris TO, et al: Life events and psychiatric disorders, Part I: Some methodological issues. Psychol Med 3:74-87, 1973

40. Brown GW, Andrews B, Harris TO, et al: Social Support, self-esteem and depression. Psychol Med 6:813-831, 1986 